\title{
Considerations and strategies for educating stroke patients with neurological deficits
}

\author{
Laura J. Griffin ${ }^{1}$, J oanne V. Hickey ${ }^{2}$ \\ 1. UT School of Nursing, Methodist Sugar Land Hospital, Sugar Land, USA. 2. School of Nursing, University of Texas Health \\ Science Center, Houston, USA.
}

Correspondence: Laura J. Griffin. Address: UT School of Nursing, Methodist Sugar Land Hospital, 16655 SW Freeway, Sugar Land, TX 77459, USA. Email: lauraj.griffin@kindred.com.

Received: October 7, 2012

Accepted: October 28, $2012 \quad$ Online Published: February 3, 2013

DOI : $10.5430 /$ jnep.v3n8p125

URL: http://dx.doi.org/10.5430/jnep.v3n8p125

\begin{abstract}
Objective: The objective of this article is to increase awareness and provide information for providers to guide educational strategies about potential obstacles encountered while educating patients with neurological deficits.

Background: Stroke is the third leading cause of death worldwide. Those who survive are often left with disabilities that decrease quality of life and increase a need for institutional care. One quarter of patients diagnosed with stroke annually have had a stroke previously. Identification of personal risk factors and learning methods for controlling them is the first steps in preventing recurrent stroke.

Conclusion: Educating patients about personal risk factors is not only a quality indicator for Joint Commission accredited stroke programs, but also education is associated with decreased readmission rates. However, the variety of neurological deficits seen in the stroke population can present a significant educational barrier.

Practice Implications: Understanding the complexity and impact of neurological deficits affecting patients who have suffered a stroke may provide improved secondary prevention efforts. Providers who are able to fully evaluate educational needs and use this knowledge to individualize stroke education are essential in improving stroke outcomes through risk factor management and early recognition of recurrent stroke.
\end{abstract}

\section{Key words}

Education, Stroke patients, Neurological deficits

\section{I ntroduction}

Stroke is the fourth leading cause of death in the United States (US). Each year approximately 795,000 patients with new strokes are diagnosed in the US ${ }^{[1]}$, resulting in more than 137,000 deaths ${ }^{[2]}$. The remaining survivors are often left with cognitive, behavioral, motor, and sensory deficits. Ninety percent of stroke survivors have some neurological deficit, and $40 \%$ live with moderate to severe impairments requiring specialized care ${ }^{[3]}$. By the year 1997, stroke was the leading cause of long-term disability ${ }^{[4]}$. By 2005, 6.5 million Americans were living with the remnants of a stroke ${ }^{[2]}$.

Recurrent strokes account for one quarter of all strokes diagnosed annually ${ }^{[5]}$. One factor related to the staggering incidence of recurrent stroke is failed secondary prevention. Secondary prevention depends upon health care consistent 
with national standards and patient understanding of personal risk factors and adherence to prescribed plans of care. Although $80 \%$ of strokes are preventable through risk factor identification and management ${ }^{[6]}$, as many as $40 \%$ of US patients who have had a stroke are unable to verbalize even one risk factor for recurrent stroke ${ }^{[7]}$. Similar findings were seen in the United Kingdom, where $45 \%$ of patients with a previous stroke could not identify any risk factor for stroke ${ }^{[8]}$.

Educating patients on how to recognize stroke symptoms and control risk factors is a quality indicator for Joint Commission accredited stroke programs ${ }^{[9]}$.

Despite concerted efforts to improve the frequency of stroke education to be in compliance with the Joint Commission mandates for stroke centers, the incidence of recurrent strokes remains steady. Between 2003 and 2008, a national stroke registry was compiled using data collected through Get with the Guidelines software produced by the American Heart Association. Results revealed that $30 \%$ of strokes diagnosed were labeled as recurrent strokes ${ }^{[10]}$. These findings are especially important within the focus of failed secondary prevention and stroke education efforts.

The Joint Commission requires that a facility meet $85 \%$ compliance with the five components of stroke education. The components are (1) risk factors involved in stroke reoccurrence, (2) warning signs of stroke, (3) how to call for emergency services, (4) follow-up care, and (5) compliance with prescribed medications ${ }^{[11]}$. Although institutions may meet the requirement of delivering the educational information, the information may not be presented in a way patients can comprehend and use the knowledge over time to prevent reoccurrences. Factors that contribute to nurses not providing appropriate instruction are time constraints and inadequate knowledge of patient education needs. In addition, nurses may not recognize how a patient's neurological deficits impede knowledge acquisition. Data from the national stroke registry suggest that even with one-on-one education, the myriad of deficits that occur with stroke can make it difficult to apply a "one fits all" approach to patient education ${ }^{[10]}$.

\section{Background and significance}

A stroke occurs when blood flow to the brain is interrupted due to an injury or occlusion of a cerebral blood vessel, which results in long lasting neurological deficits. The area of the brain affected by stroke is directly related to the specific cerebral blood vessel involved. A complex web of blood flow and perfusion influences the varying symptoms that occur in a patient. Since the brain is an extremely complex organ with cognitive, behavioral, motor, and sensory functions attributed to different areas, any injury may result in a variety of neurological deficits, whether transient or long term ${ }^{[12]}$.

Currently, nursing consideration for the provision of stroke patient education leans more to presenting written materials rather than investigating other methods for delivery of educational content. Nurses do not generally assess the patient's learning needs to understand potential barriers to learning or inquire about the patient's preferred method of learning. While some people learn best by listening to the information in a one-on-one format, others may prefer to learn by reading or interacting with the material.

In dealing with the stroke population, nurses should be aware of any neurological deficits that may affect learning ability. For example, patients with a visual deficit may find dealing with pamphlets and reading materials frustrating due to loss of vision, visual field deficits, or diplopia. Instead, these patients tend to favor auditory methods of learning, and materials presented using either auditory methods or a written format with large print and contrasting colors may be the most beneficial ${ }^{[13]}$. In contrast, auditory methods are the least effective educational strategy for patients with a hearing deficit. Instead, a written format is a more reliable method of communicating than an auditory one ${ }^{[13]}$. For these patients, written information should be provided in a clear and concise manner. However, information in auditory form can be given to patients with some residual hearing, especially if they are able to adjust the sound amplitude. 
Another common neurological deficit encountered in the stroke population pertains to language deficits. Dealing with a language deficit, such as aphasia, often provides the most frustration for patients and healthcare professionals. Aphasia includes difficulties in understanding or creating written or spoken language. Whereas expressive aphasia is an inability to express oneself through written or spoken words, receptive aphasia is an inability to understand written or spoken language. Stroke survivors who have both expressive and receptive aphasia suffer from global aphasia ${ }^{[14]}$. Being unable to communicate through language poses a significant challenge to the health educator. It is frequently necessary to provide information to patients using symbols or by demonstrating the behaviors desired.

\section{Learning principles}

A review of the learning process and how memory works illustrates the need to apply learning principles when addressing the special needs of stroke patients. Knowledge about the learning process is helpful with promoting advocacy for patient centered care and further justifies the need for individualized educational plans. Select landmark studies were used to compile the following general learning and memory processes ${ }^{[15-18]}$.

\subsection{Memory}

In learning, patients acquire new information through instruction or experience. However, acquiring new knowledge would be useless unless the information learned is stored for later retrieval. Memory allows individuals to use past experiences to make decisions on the best way to respond to future events. Memory involves a process of encoding, storing, and retrieval of information. Both presentation of information and memory of material are required for effective learning to occur ${ }^{[17]}$.

Individuals have both short-term and long-term memory. Short-term memory is comprised of both the sensory and working memory ${ }^{[17]}$. Large amounts of sensory input constantly bombard the brain, and the majority of this input is filtered subconsciously in sensory memory where it is held for approximately 20 seconds ${ }^{[19]}$. Whether or not a sensory impulse moves into consciousness depends on the individual's perception of importance. If sensory input is recognized as important, it is brought to consciousness and moved into the working memory, which is able to receive input from either sensory memory or via retrieval from long-term memory ${ }^{[20]}$. In 1974, the model of working memory comprised of a central control mechanism and two support systems, the phonological loop and the visuospatial sketchpad was introduced ${ }^{[20]}$. The phonological loop processes auditory input and memories, whereas the visuospatial sketchpad processes and temporary stores visual and spatial information.

Several factors can limit a person's ability to store information. The working memory of an adult is able to successfully hold seven data points at a time ${ }^{[16]}$. However, this number may increase by chunking individual data into small groups. Not only is the working memory found to be limited in its capacity to hold a restricted number of data points, but also it is restricted by time. The average adult can only process items in working memory for 10-20 minutes before mental fatigue or boredom caused the individual's focus to drift ${ }^{[18]}$. Being aware of these number and time limitations are important for educators, since over tasking the working memory can jeopardize the facilitation of information into long term memory.

\subsection{Encoding}

Converting information from short-term to long-term memory involves a complex neural process ${ }^{[15]}$. Before data can be placed into long-term memory, it must be encoded. Encoding occurs when attention, understanding, and relevance are applied to sensory input. Attention, or conscious awareness, brings the information from sensory memory into working memory. While in the working memory, the learner must be able to apply new information to past experiences to understand or make sense of the information. By creating these associations, the learner begins to understand how this information may be used in the future. 
Attention and understanding are necessary building blocks for the conversion of information into long-term memory, but without relevance the information may not be stored. Relevance is perceived when the information directly and personally impacts the learner. Once these criteria are met, the information is processed in the hippocampus and stored throughout the cortex as an engram, or representation of a memory ${ }^{[18]}$. For instance, the memory of a birthday party would be not be stored as one intact memory, but would be stored as fragments in the different areas of the brain. The visual memory of the party may be stored in the occipital area, whereas the auditory memory may be stored in parts of the brain responsible for processing sound. Injuries to any part of the brain involved in processing or storage of memory can significant impair memory and learning. As many as $30 \%$ of stroke survivors, have some level of memory impairment ${ }^{[21]}$.

\subsection{Retrieval and forgetting}

After information is stored in the long-term memory, future use of the information requires retrieval ${ }^{[22]}$. During retrieval, the individual attempts to remember consciously or is aided by an associational trigger, such as a smell or a sound. The brain then accesses the various sites of storage to recreate the complete memory. However, not all information is available for retrieval. Since the brain is constantly bombarded with large amounts of data, forgetting allows the brain to discard irrelevant information that can interfere with the acquisition, storage, and retrieval of essential information. Encoding failures may provide one explanation of why individuals forget ${ }^{[22]}$. Whereas some theorize that, overtime, stored memories decay or fade; others suggest that similar or competing memories confuse the process ${ }^{[23]}$. Whatever the cause, forgetting is a constant obstacle for learners. Forgetting may begin as quickly as the information is provided, with the majority of forgetting occurring during the first 18-24 hours after knowledge acquisition ${ }^{[22]}$. Therefore, 24 hours is considered a reasonable guideline to assess whether or not the information learned was remembered.

The retrieval process is especially important in the stroke population ${ }^{[24]}$. Prospective memory or the ability to remember to perform an action is essential for successful secondary prevention. Patients had a significant decline in prospective memory after stroke as compared to controls. This can have a significant impact on rehabilitation and health promotion. Often stroke patients have co-morbidities such as hypertension and diabetes, which require them to remember to check their blood sugar or blood pressure and take their medications. Having an educational medium that allows for reinforcement of important concepts through repetition may be one strategy to improve prospective memory and patient adherence.

\section{Patient education}

Currently, patient centered care is replacing a disease-centered model. In the disease-centered model, providers made treatment decisions based on clinical experiences, laboratory results, and diagnostic data. Conversely, in the patient centered model, patients are made active participants in their own care with treatments focused on their needs and preferences. By asking patients to take an active role to improve and sustain their health, the health care community is encouraging empowerment. The goal of patient education is to provide knowledge that allows the patient to engage in behaviors to improve, restore, or maintain health. Knowledge acquisition is therefore, a necessary prerequisite for change. By increasing patients' knowledge about health conditions, risk factors, and treatments, the health care team can encourage active involvement and improve self-efficacy ${ }^{[25]}$.

Prior to administering patient education, potential participants should be assessed for learning preferences and potential barriers, such as cognitive, language, literacy, hearing and vision defects, that may impede knowledge acquisition ${ }^{[13]}$. By assessing the patient's needs and preferences, the health educator places the patient in the center of the educational plan. However, benchmarks regarding educational programs only state that the information needs to be provided; guidelines do not necessarily prescribe methods or identify a metric for evaluating the effectiveness of delivery. To ensure an effective educational session, specific objectives as well as a method for evaluation should be determined before the start of the informational session ${ }^{[26]}$. 


\section{Stroke education}

Currently, the only treatment available to reverse or limit long-term disability after acute ischemic stroke is tissue plasminogen activator ( $t$-PA) ${ }^{[27]}$. To be eligible for $t$-PA, the patient must present to the emergency department (ED) within 3 hours of first symptoms. When the time of symptom onset is unclear, time last seen normal is used instead. Only $3 \%$ of patients meet the 3-hour administration window and are able to receive the drug ${ }^{[28-30]}$. Excluding hemorrhagic stroke, the most common reason patients are ineligible for t-PA is related to delayed presentation ( $>3$ hours) ${ }^{\text {[31-34] }}$. Delayed presentation was attributed to lack of patient knowledge of risk factors and stroke symptoms ${ }^{[7]}$. These findings were substantiated by a study that found the median time from first stroke symptoms until emergency department (ED) presentation to be 16 hours ${ }^{[35]}$. The authors also found the severity of symptoms affected the patient's decision to seek care. Signs and symptoms other than paralysis were frequently overlooked or misinterpreted, and only when paralysis was present did patients routinely seek prompt care.

The above findings coupled with the estimate that $14 \%$ of people suffering an acute stroke will have another stroke within 12 months, prompted the American Stroke Association (ASA) and the Brain Attack Coalition (BAC) to add patient education to their guidelines ${ }^{[36]}$. Taking cues from ASA and BAC, the Joint Commission mandated stroke education for patients as one of the performance measures required for stroke certified hospitals ${ }^{[27]}$.

The goal of stroke education is to give patients and caregivers the tools to control risk factors and speed access to care when stroke symptoms occur, thereby preventing or limiting further disability from recurrent stroke. However, only a small number of articles address the best methods of presenting this information ${ }^{[37-39]}$. The majority of literature related to patient education for stroke patients is geared to informing healthcare providers of the importance of educating patients ${ }^{[40,41]}$. Most patient focused literature is devoted to helping patients through the rehabilitation phase. Few articles discussed the best way to educate stroke patients about the importance of recognizing and preventing stroke. Studies have identified perceived inadequacies of stroke education by both patients and their families ${ }^{[42,43]}$. In a sample of 164 stroke patients, $89 \%$ were satisfied with their medical treatment, while $49 \%$ were dissatisfied with the information that they received while hospitalized ${ }^{[44]}$.

\section{Educational strategies}

Several different methods of presenting stroke information have been evaluated, but no one strategy has been shown to be the most effective ${ }^{[45]}$. The most commonly reported strategy involved the use of written materials, which are cost effective and easily distributed. A drawback to using written materials is that they are only effective for literate patients with adequate sight. Older adults and patients with cognitive deficits may have lower levels of literacy. Residual deficits, such as receptive aphasia and visual impairment, make use of written materials a less effective choice. If used, written materials should be scripted at the lowest reading level possible while still conveying the information accurately ${ }^{[46]}$.

Often, readability of the material presented is not assessed. Studies that examined the effectiveness of written educational materials with stroke patients did not find written material to be more effective than face-to-face education ${ }^{[46-50]}$. These study results suggest that readability may be a limiting factor. Hoffman et al. evaluated several sets of written materials given to 57 stroke patients and 12 caregivers ${ }^{[46]}$. The estimated mean reading level of the written materials was 11 th grade, while the average patient reading level was only 7-8th grade. As the patients' reading level appears to effect ability to understand written materials, educators should evaluate readability prior to disbursement.

Interactive computerized multimedia educational (ICME) programs that incorporate voice may provide a better avenue for understanding the material presented. Few published studies exist that examine the use of ICME programs as a means to educate the stroke population. One study using computerized multimedia in the stroke population did not find a statistical 
difference of knowledge acquisition between verbal and computerized education, though several limitations in the study may have impacted outcomes such as the exclusion of patients with visual deficits and aphasia ${ }^{[38]}$.

\section{Educating patients with disabilities}

Stroke patients are often left with a variety of deficits and disabilities that add an additional dimension to developing teaching plans. Since stroke patients may experience a myriad of neurological deficits and long-term disabilities, health educators should consider the impact that disabilities have on knowledge acquisition and adapt materials and information accordingly.

Disabilities affecting learning are generally behavioral, sensory, and cognitive disabilities. Motor disabilities are not thought to impact learning. However, this may be misleading due to the advances in technology. Since many Americans now rely on computers to access health information, an upper extremity motor disability may impact on the patient's ability to use a computer (or use it without special software and assisting devices) and thereby limit access to information. Rarely will this affect the patient in the acute care setting, but it should be considered when designing health promotion education meant for patients along the continuum of care, during recovery, and with chronic illness.

A plethora of literature addresses cognitive and behavioral disabilities affecting the pediatric population and special education teachers. A review of EBSCO, PubMed, and Cochrane Systematic Review Databases, using the keywords "patient education" and "disability" and limiting the search to adults and clinical trials, identified 188 articles. The majority of the articles focused on patients with chronic pain rather than with neurological deficits. This finding is not surprising, given that the Centers for Disease Control and Prevention (CDC) lists arthritis and chronic back pain as the top two causes of disability in adult Americans ${ }^{[51]}$. While pain can affect learning by decreasing concentration, these articles were excluded because pain syndromes are not a focus of this review. This leaves a clear absence of literature regarding methods of educating adults with sensory, motor, behavioral, and cognitive disabilities. Consequently, extrapolation from pediatric studies may be necessary to fill knowledge gaps.

\subsection{Sensory disabilities}

Sensory disabilities refer to impairments in sight, hearing, smell, touch, or taste. Of these, sight and hearing have the greatest impact learning. People with long standing sensory disabilities often compensate by developing increased acuity in another sense. When possible, the health educator should capitalize on this compensatory mechanism. A newly diagnosed stroke patient will not have yet learned to compensate, therefore, the educator should ascertain the length of time that the disability has been present.

Since up to $80 \%$ of learning takes place through visual input, visual impairments can directly affect the education process ${ }^{[52]}$. For the purpose of this review, visual impairment is defined as reduction of vision that cannot be corrected with standard glasses or contact lenses. Visual impairment thus ranges from low vision to complete blindness.

In 2008, visual impairment, as defined above, was known to affect 3.3 million Americans over the age of $40^{[53]}$. This number will continue to rise as the population becomes progressively older. The older adult may have visual impairments caused by macular degeneration, cataracts, glaucoma, diabetic retinopathy, occipital lobe tumor, or stroke. Since any of these visual impairments can directly impact learning, learning implications for the visually impaired should be considered whenever developing a teaching plan. The National Dissemination Center for Children with Disabilities recently recommended that technology in the form of computers as well as optical and video aids should be used to educate children with visual impairment ${ }^{[54]}$. Visual aids that may be useful when reading educational material are prescriptive spectacles, magnifying glasses, or telemicroscopes ${ }^{[55]}$. Other methods that may augment the learning processes are large print written materials, books in Braille or on tape, computers, or talking devices ${ }^{[13,55]}$. 
Likewise, consideration for people with a hearing impairment should also be incorporated into teaching plans. Hearing impairment, defined as a decreased ability to hear or differentiate sounds, ranges from mild hearing loss to deafness. In a 2007 publication, it was estimated that 37 million adults were hearing impaired ${ }^{[56]}$. Length of time and severity of hearing loss should be determined to fully gauge necessary educational adjustments. For instance, patients deaf since birth may not have the ability to understand verbal or written language, and using sign language or Braille materials may be the only option. For adults who have acquired hearing loss after language acquisition, written materials may be the most suitable method for providing educational information ${ }^{[13]}$. Adults who have some residual hearing may still be able to acquire knowledge through verbal instruction with the use of auditory and visual aids. Hearing and visual aids such as augmented speakers, pictures, diagrams, or animations may aid in knowledge acquisition in this population ${ }^{[13]}$.

\subsection{Cognitive disability}

Some degree of cognitive deficits occurs in more than half of stroke survivors ${ }^{[57,58]}$. Despite its prevalence, standardized definitions for cognitive disability are ambiguous. Depending on the literature reviewed, behavioral and intellectual disability may be described separately or together. For the purpose of this review, cognitive disability describes both behavioral and intellectual disability and is defined as impairment in the ability to access, process, or remember information. Cognitive disabilities include impairments in communication, attention, memory, and executive functions. Depending on the severity, cognitive disabilities may provide the most frustrating obstacle for educators.

\subsubsection{Communication deficits}

Communication, the act of sending, receiving, and comprehending information, may be impaired in patients following a stroke. Human beings receive and send information via words, tone of voice, touch, and body language. Depending on the location of injury, stroke patients may have damage in one or more of the centers required for effective communication. An injury to Broca's area may result in expressive aphasia, an inability to communicate through written or spoken language. An injury to Wernicke's area may result in receptive aphasia, an inability to understand written or spoken language. Injury to both speech centers, resulting in global aphasia, may render the patient completely unable to understand or communicate using written or spoken language ${ }^{[14]}$.

While aphasia is the most common cause of communication deficit in patients following a stroke, injuries that do not directly affect the speech centers can still cause language deficits due to alterations in intellect ${ }^{[14]}$. Patients with mild cognitive impairment and without injury to speech centers may be able to communicate with speech. However, patients with moderate to severe disabilities may be unable to comprehend any spoken language, and non-verbal forms of communication, such as gestures, body language, and facial expressions, are more influential than verbal communication. This suggests that educators should apply non-verbal forms of knowledge when communicating with intellectually disabled patients ${ }^{[59]}$.

As gestures and speech are two separate communication systems, gestures may function as a backup system when language deficits are present ${ }^{[60]}$. Several studies have successfully used gestures paired with verbal production to treat naming impairments in patients with aphasia ${ }^{[61-63]}$.

\subsubsection{Attention and memory impairments}

Attention, the ability to concentrate on one stimulus while ignoring others, is often impaired in stroke patients. Studies estimate that $46 \%$ to $92 \%$ of stroke survivors have some degree of attention deficit ${ }^{[57,64,65]}$. Since attention is required for effective learning and rehabilitation, attention deficits can negatively impact secondary prevention and recovery as well as lead to memory impairment post stroke. Though less common than attention deficits, memory impairment may be seen in as much as $30 \%$ of stroke survivors ${ }^{[21,57]}$. Arvanitakis, Leurgans, Barnes, Bennett, and Schneider found that patients with mulitple cortical or micro-infarcts were more susceptible to global cognitive decline and deficits in semantic and episodic memory than those without these deficits ${ }^{[66]}$. 
The majority of literature on educating people with cognitive disabilities has focused on children. Populations commonly included are those with cerebral palsy, mental retardation, Down's syndrome, traumatic brain injury, autism, and attention deficit disorder. The literature for the child with acquired brain injury commonly focuses on behavioral management, social training, and the performance of activities of daily living. On the other hand, literature for the child with attention deficit disorder describes strategies including behavior management, self-monitoring, and positive reinforcement.

Researchers often exclude patients with dementia and aphasia from research studies thus limiting the literature regarding the best methods for educating adults with cognitive deficits. For example, four studies involving the education of neurological patients excluded those with dementia and aphasia ${ }^{[38,67-69]}$. This deficit suggests that the educator takes into account that educational strategies should be individualized because patients with cognitive disabilities may have a wide range of communication and cognitive abilities that impact learning.

Ideally, the patient's capacity to learn should be assessed prior to administration of educational activities ${ }^{[70]}$. Neuropsychologists use a variety of psychomotor tests to identify deficits in attention, memory, language, executive functions, visuospatial, visuomotor, and motor processes and can identify discrepancies between a patient's capacities to learn and subjective performance. Comprehensive neuropsychological testing takes several hours to complete and is not available in most acute care settings. The lack of this information often leaves the health educator with only a gross assessment of learning capability. While individuals with cognitive deficits should undergo neuropsychological testing, testing will most likely need to be completed on an outpatient basis ${ }^{[70]}$. With limited objective information regarding cognitive function, presenting health promotion information to patients with cognitive disabilities continues to remain a challenge in the acute care setting.

\section{Technology in education}

Using technology to deliver education through multimedia is becoming an expectation in the rapidly developing technological world and may provide additional strategies to aid in the education of patients with various disabilities. First described in the 1950-1960's, an Ohio State University, Professor Edgar Dale, popularized the use of multimedia in education ${ }^{[71]}$. Often referred to as the father of modern media in education, Dale's seminal work produced the often cited tenet that people remember $10 \%$ of what they read, $20 \%$ of what they hear, and $30 \%$ of what they see, $50 \%$ of what they see and hear, and $90 \%$ of what they see, hear, and do ${ }^{[71]}$. Therefore, using multiple avenues for education provides the best chance for effective knowledge acquisition and retention.

Instructional technology theories combined with the rapid advancement of technologic devices have impacted education not only in classrooms but also in clinics and hospitals. Currently, health information can be delivered in several ways (e.g. audiotapes, free standing computer programs, instructional digital video disc (DVD) and online or downloadable electronic programs). The national focus on health promotion and education has health educators searching for cost effective strategies to educate large groups of people with limited time and staff. However, cost, access, and technological support should be considered before using technology for educational purposes.

In light of the explosion of technology and corresponding research over the past ten years, a literature review of the use of technology was limited to free standing interactive multimedia computer programs, the type of technology used in the creation of this educational program. However, it is recognized that other forms of multimedia, such as the many forms delivered online or instructional DVD, may be suitable for the education of stroke patients.

\section{Gaps in the literature}

A gap exists in the literature describing types and effectiveness of various educational methodologies in the stroke population. In the literature that describes methodologies of educating patients in general, the studies employed English 
language materials and instructions. In the United States, immigrants for whom English is a second language may have difficulty reading, comprehending, and using health information to make decisions and follow treatment advice ${ }^{\text {[72] }}$. Although non-English studies were not reviewed, such studies may exist. However, the translation of successful print and multimedia programs in languages of patients most commonly inhabiting specific locales (i.e. Spanish, Mandarin, Vietnamese) is not prevalent in literature.

A specific gap is noted in literature pertaining to patients with cognitive deficits, and specifically, in relation to patients with cognitive impairment as a result of stroke. While patients with severe cognitive deficits may not be able to participate in a multimedia interactive program, by engaging multiple areas of the brain, those with mild deficits may benefit from such programs as much as or more so than patients with intact cognitive abilities.

Although literature is plentiful in relation to educating children, less is available on educating older adults, specifically post stroke older adults. Extending this gap is that there is a dearth of literature on educating the elderly. Older adults were a minority among study participants. Further studies that include patients who have barriers to literacy, are over 65 years of age, or have cognitive disabilities, should be considered to bridge gaps in literature.

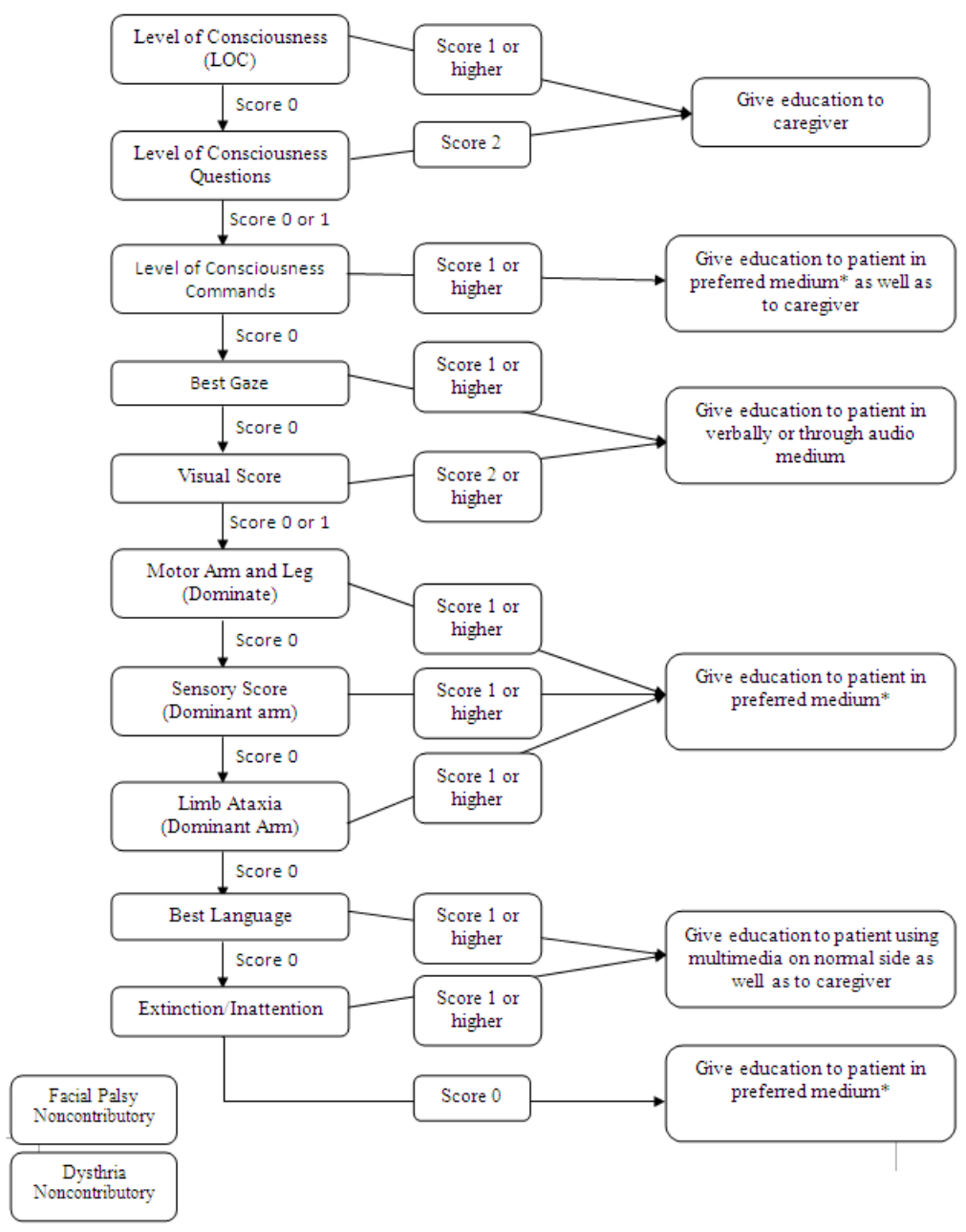

Figure 1. Educational Medium Decision Aid for the Neurological Patient * consider patient preference after ascertaining literacy and reading level. 


\section{Practice implications}

Neurological assessment and identification of learning needs are the hallmarks for choosing an appropriate educational medium. Nurses may view giving stroke information in a form other than print costs them time is a barrier that could conceivably limit thorough assessment of educational needs. In order to assist health care providers in identifying the most appropriate methods for presenting educational information to patients with neurological deficits, the authors suggest combining a widely used assessment tool with a decision algorithm.

The most commonly used neurological assessment tool in the stroke population is the National Institutes of Health Stroke Scale (NIHSS). The NIHSS aids the nurse through 11 detailed steps to identify potential neurological deficits. Using the scale as a basis for the assessment, the authors propose a decision aid to facilitate the educational process as shown in Figure 1. Through identification of neurological deficits, the provider can choose an educational medium that makes use of the unaffected areas of the brain for learning, thereby increasing the probability of understanding and remembering the information provided. In patients with language or severe neurological deficits, this task may be somewhat more difficult. While currently little research has been focused on the stroke population, the use of multimedia may allow for several areas of the brain to be supplied with information thereby improving the chances for retention.

During the acute phase after stroke, the impact of neurological deficits may not be readily apparent. The authors therefore recommend involving the family or direct care givers in all educational efforts. By giving education to the patient's family members, the information can be reinforced during the post acute phase by those who have also received education.

\section{Conclusion}

Patients with disabilities, due to sensory and cognitive deficits, may require alternative methods of education. Research findings indicate that patients are generally uneducated about stroke including risks and symptoms of recurrent stroke. This lack of knowledge leads to an increased incidence of disease and disability. By improving stroke literacy, the health educator can improve patient self-efficacy and decrease delays in treatment. While there are significant gaps in the literature regarding the best methods for educating patients about stroke, several of the above key concepts can be extrapolated to provide the framework for any stroke educational program.

\section{References}

[1] American Heart Association Stastitics Committee and Stroke Statistics Subcommittee. Heart disease and stroke statistics-2012 update: A report for the American Heart Association. Circulation. 2012;125:e2-e220. PMid:22179539 http://dx.doi.org/10.1161/CIR.0b013e31823ac046

[2] American Heart Association. Impact of stroke. [Internet] 2012. Available from http://www.strokeassociation.org/STROKEORG/AboutStroke/Impact-of-Stroke-Stroke-statistics_UCM_310728_Article.jsp

[3] National Stroke Association. Rehabiliation Therapy after Stroke [Internet]. 2011. Available from http://www.stroke.org/site/PageServer?pagename=REHABT

[4] Hoyert D L, Kochanek K D, Murphy S L. Deaths: Final data for 1997. National Vital Statisitic Report. 1999;47:1-104.

[5] Hankey GJ. Secondary prevention of recurrent stroke. Stroke; 2005; 36: 218-21. PMid:15637323 http://dx.doi.org/10.1161/01.STR.0000153048.87248.3b

[6] National Stroke Association. Stroke Prevention [Internet]. 2001. Available from http://www.stroke.org/site/PageServer?pagename=prevent

[7] Kothari R, Sauerbeck L, Jauch E, Broderick J, Brott T, Koury J, Liu T. Patients' awareness of stroke signs, symptoms, and risk factors. Stroke. 1997; 28: 1871-75. PMid:9341687 http://dx.doi.org/10.1161/01.STR.28.10.1871

[8] Slark J, Bentley P, Majeed A, Sharma P. Awareness of stroke symptomatology and cardiovascular risk factors amongst stroke survivors. J Stroke Cardiovasc Dis. 2012; 21: 358-62. PMid:21111631

http://dx.doi.org/10.1016/j.jstrokecerebrovasdis.2010.09.010 
[9] The Joint Commission. Facts about primary stroke center certification [Internet]. 2009. Available from: http://www.jointcommission.org/assets/1/18/Primary_Stroke_Center_Certification.pdf

[10] Schwamm L H, Reeves M J, Wenqin P, Smith EE, Frankel M R, Olson D, Zhao X, Peterson E, Fonarow G C. Race/ethnicity, quality of care, and outcomes in ischemic stroke. Circulation. 2010; 121: 1492-501. PMid:20308617 http://dx.doi.org/10.1161/CIRCULATIONAHA.109.881490

[11] Joint Commission. Stroke performance measurement implementation guide [Internet]. 2008. Available from http://www.jointcommission.org/assets/1/18/stroke_pm_implementation_guide_ver_2a.pdf

[12] Scott P, Timmerman C. Stroke syndromes. In: Tintinalli JE, Kelen GD, Stapczynski JS (Eds.) Emergency Medicine New York: McGraw-Hill; 2004. p. 1383-90.

[13] Bastable, S. Nurses as educator: Principles of teaching and learning for nursing practice. Sudbury, Massachusetts: Jones and Bartlett Publishers; 2008.

[14] Ropper AH, Samuels MA. Disorders of Speech and Language. In Adams and Victor's principles of neurology New York: McGraw-Hill Companies, Inc.; 2009. p. 461-481.

[15] Brown J. Some tests of the decay theory of immediate memory. Quart J of Exp Psych. 1958; 10: 12-21. http://dx.doi.org/10.1080/17470215808416249

[16] Miller GA. The magical number seven, plus or minus two: Some limits on our capacity for processing information. Psychol Rev. 1956; 63: 81-97. PMid:13310704 http://dx.doi.org/10.1037/h0043158

[17] Atkinson RC, Shiffrin RM. Human memory: A proposed system and its control processes. In Atkinson RC, Shiffrin RM, Spence KW, Spence JT, editors. The psychology of learning and motivation. New York, NY Academic Press; 1968. P 98-195.

[18] Russell P. The brain book. New York, New York: Plume; 1979

[19] Peterson LR, Peterson MJ. Short term retention of individual verbal items. J Exp Psychol. 1956; 58: 193-198. http://dx.doi.org/10.1037/h0049234

[20] Baddeley A D, Hitch G. Working memory. In Baddeley AD, Hitch G, editors. The psychology of learning and motivation: Advances in research and theory New York, NY: Academic Press; 1974. p. 47-89.

[21] Sundar U, Adwani S. Post-stroke cognitive impairment at three months. Ann Indian Acad Neurol. 2010; 13 : $42-46$. PMid:20436746 http://dx.doi.org/10.4103/0972-2327.61276

[22] Sousa D. How the brain learns. Thousand Oaks, California: Corwin Press; 2006.

[23] Altmann EM, Gray WD. Forgetting to remember: The functional relationship of decay and interference. Psychol Sci. 2002; 13: 27-33. http://dx.doi.org/10.1111/1467-9280.00405

[24] Kim HJ, Craike FL, Luo L, Ween JE. Impairment in prospective and retrospective memory following stroke. Neurocase. 2009; 15: 145-56. PMid:19296397 http://dx.doi.org/10.1080/13554790802709039

[25] Jones F, Mandy A, Partridge C. Changing self efficacy in individuals folowing first time stroke: preliminary study of a novel self management intervention. Clin Rehabil. 2009; 23: 522-33. PMid:19403556 http://dx.doi.org/10.1177/0269215508101749

[26] Friedman AJ, Cosby R, Boyko S, Hatton-Bauer J, Turnbull G. Effective teaching strategies and methods of delivery for patient education. J Cancer Educ. 2010; 26: 12-21. PMid:21161465 http://dx.doi.org/10.1007/s13187-010-0183-x

[27] Albers GW, Bates VE, Clark WM, Bell R, Verro P, Hamilton SA. Intravenous tissue-type plasminogen activator for treatment of acute stroke: The standard treatment with alteplase to reverse stroke (STARS) study. JAMA. 2000; 283: 1145-50. PMid:10703776 http://dx.doi.org/10.1001/jama.283.9.1145

[28] Clark WM, Wissman S, Albers GW, Jhamandas JH, Madden KP, Hamilton S. Recombinant tissue-type plasminogen activator for ischemic stroke 3 to 5 hours after symptom onset: The ATLANTIS study: A randomized controlled trial. JAMA. 1999; 282; 2019-26. PMid:10591384 http://dx.doi.org/10.1001/jama.282.21.2019

[29] National Institute of Neurological Disorders and Stroke. tPA Stroke Study Group. Tissue plasminogen activator for acute ischemic stroke. N Engl J Med. 1995; 333: 1581-1587. PMid:7477192 http://dx.doi.org/10.1056/NEJM199512143332401

[30] Marler JR, Tilley BC, Lu M, Brott TG, Lynden PC, Grotta JC, Broderick JP, Levine SR, Frankel MP, Horowitz SH, Haley EC, Lewandowski CA, Kwiatkowski TP. Early stroke treatment associated with better outcome: The NINDS rt-PA stroke study. Neurology. 2000; 55: 1649-1655. PMid:11113218 http://dx.doi.org/10.1212/WNL.55.11.1649

[31] Morris DL, Rosamond W, Madden K, Schultz C, Hamilton S. Prehospital and emergency department delays after acute stroke: The Genetech stroke presentation survey. Stroke. 2000; 31: 2585-90. PMid:11062279 http://dx.doi.org/10.1161/01.STR.31.11.2585

[32] Rosamond WD, Gorton RA, Hinn AR, Hohenshaus SM, Morris DL. Rapid response to stroke symptoms: The delay in accessing stroke healthcare (DASH) study. Acad Emerg Med. 1998; 5: 45-51. PMid:9444342 http://dx.doi.org/10.1111/j.1553-2712.1998.tb02574.x 
[33] Schroeder EB, Rosamond WD, Morris DL, Evenson KR, Hinn AR. Determinants of use of emergency medical services in a population with stroke symptoms: The second delay in accessing stroke healthcare (DASH II) study. Stroke. 2000; 31: 2591-96. PMid:11062280 http://dx.doi.org/10.1161/01.STR.31.11.2591

[34] Webster P, Radberg J, Lundgren B, Peltonen M. Factors associated with delayed admission to hospital and in-hospital delays in acute stroke and TIA: A prospective, multicenter study. Stroke. 1999; 30: 40-8. http://dx.doi.org/10.1161/01.STR.30.1.40

[35] Zerwic J, Hwang SY, Tucco L. Interpretation of symptoms and delay in seeking treatment by patients who have had a stroke: Exploratory study. Heart Lung. 2007; 36: 25-34. PMid:17234474 http://dx.doi.org/10.1016/j.hrtlng.2005.12.007

[36] Summers D, Leonard A, Wentworth D, Saver JL, Simpson J, Spilker JA, American Heart Association Council on Cardiovascular Nursing and the Stroke Council. Comprehensive overview of nursing and interdisciplinary care of the acute ischemic stroke patient: A scientific statement from the american heart association. Stroke. 2009; 40: 2911-44. PMid:19478222 http://dx.doi.org/10.1161/STROKEAHA.109.192362

[37] Hoffman T, McKenna K. Analysis of stroke patients' and carers' reading ability and the content and design of written materials: Recomendations for improving written stroke information. Patient Educ Couns. 2006; 60: 286-93. PMid:16098708 http://dx.doi.org/10.1016/j.pec.2005.06.020

[38] Maasland E, Koudstaal PJ, Habbema JD, Dippel D W. Effects of an individualized multimedia computer program for health education in patients with a recent minor stroke or transient ischemic attack: A randomized control trial. Acta Neurol Scand. 2007; 115: 41-8. PMid:17156264 http://dx.doi.org/10.1111/j.1600-0404.2006.00722.x

[39] Yvonne Chan YF, Nagurka R, Richardon LD, Zaets SB, Brimacombe MB, Levine S R. Effectiveness of stroke education in the emergency department waiting room. J Stroke Cerebrovasc Dis. 2010; 19: 209-15. PMid:20434048 http://dx.doi.org/10.1016/j.jstrokecerebrovasdis.2009.04.009

[40] Barrere C, Delaney C, Petersen D, Hickey K. Primary stroke center education for nurses: Improving core measures. J Nurs Adm. 2010; 40: 515-21. PMid:21084886 http://dx.doi.org/10.1097/NNA.0b013e3181fc1a05

[41] Smith LN, Craig LE, Weir CJ, McAlpine CH. Stroke education for healthcare professionals: Making it fit for purpose. Nurse Educ Today. 2008; 28: 337-47. PMid:17881095 http://dx.doi.org/10.1016/j.nedt.2007.06.008

[42] Hanger H, Walker G, Paterson L, McBride S, Sainsbury R. What do patients and their careers want to know about stroke? A two-year follow-up study. Clin Rehab. 1998; 12: 45-52. PMid:9549025 http://dx.doi.org/10.1191/026921598668677675

[43] Rodgers H, Bond S, Curless R. Inadequacies in the provision of information to stroke patients and their families. Age Ageing. 2001; 30: 129-33. PMid:11395342 http://dx.doi.org/10.1093/ageing/30.2.129

[44] Wellwood I, Dennis MS, Warlow CP. Perceptions and knowledge of stroke among surviving patients with stroke and their carers. Age Ageing. 1994; 23: 293-8. PMid:7976775 http://dx.doi.org/10.1093/ageing/23.4.293

[45] Teuschi Y, Brainin M. Stroke education: Discrepancies among factors influeinging prehospital delay and stroke knowledge. Int J Stroke. 2010; 5: 187-208. PMid:20536616 http://dx.doi.org/10.1111/j.1747-4949.2010.00428.x

[46] Hoffman T, McKenna K, Worrall L, Read SJ. Randomised trial of a computer-generated tailored written education package for patients following stroke. Age Ageing. 2007; 36: 280-6. PMid:17360794 http://dx.doi.org/10.1093/ageing/afm003

[47] Lomer M, McLellan DL. Informing hospital patients and their relatives about stroke. Clin Rehab. 1987; 1: 33-7. http://dx.doi.org/10.1177/026921558700100108

[48] Lorene L, Sturney P, Brittain H. Evaluation of a meta-cognitive strategy to improve the information gained from a stroke information pack. Stress Medicine. 1992; 8: 111-2. http://dx.doi.org/10.1002/smi.2460080209

[49] Mant J, Carter J, Wade D. The impact of an information pack on patients with stroke and their carers: A randomized control trial. Clin Rehab. 1998; 12: 465-76. PMid:9869250 http://dx.doi.org/10.1191/026921598668972226

[50] Pain HS, Mclellan DL. The use of individualized booklets after stroke. Clin Rehab. 1990; 4: 265-72. http://dx.doi.org/10.1177/026921559000400403

[51] Centers for Disease Control \& Prevention. Prevalence and most common causes of disability among adults [Internet]. Morbidity Mortality Weekly Report; 2009. Available from: http://www.cdc.gov/mmwr/preview/mmwrhtml/mm5816a2.htm

[52] Farrald RR, Schamber RG. A diagnostic and prescriptive technique: Handbook 1-A mainstream approach to identification and amelioration of learning disabilities. Sioux Falls, SD: Adapt Press, 1973.

[53] National Eye Institute. Vision loss from eye diseases will increase as Americans age [Internet]. 2008. Available from: http://www.nei.nih.gov/news/pressreleases/041204.asp

[54] National Dissemination Center for Children with Disabilities. Blindness and Visual Impairment [Internet]. (n.d.). Available from: http://www.nichcy.org/Disabilities/Specific/Pages/VisualImpairment.aspx

[55] Rosenburg EA, Sperazza LC. The visually impaired patient. Am Fam Physician. 2008; 77; 1431-6.

[56] Pleis, J. R., \& Lethbridge-Cejku, M. 2007. Summary health statistics for US adults: National health interview survey [Internet]. 2006. Available from: http://www.cdc.gov/nchs/data/series/sr_10/sr10_235.pdf 
[57] Hochstenbach J, Mulder T, van Limbeek J, Donders R, Schoonderwaldt H. Cognitive decline following stroke: A comprehensive study of cognitive decline following stroke. J Clinl Exp Neuropsychol. 1998; 20: 503-17. PMid:9892054 http://dx.doi.org/10.1076/jcen.20.4.503.1471

[58] Nys GM, van Zandvoort MJ, de Kort PL, Jansen BP, de Haan EH, Kappelle LJ. Cognitive disorders in acute stroke: Prevalence and clinical determinants. Cerebrovasc Dis. 2007; 23: 408-16. PMid:17406110 http://dx.doi.org/10.1159/000101464

[59] Tuffrey-Wigne I, McEnhill L. Communication difficulties and intellectual disability in end of life care. In J Palliat Nurs. 2008; 14: 189-94.

[60] Hadar U, Wenkert-Olenik D, Krauss RM, Soroker N. Gesture and the processing of speech: Neuropsychological evidence. Brain Lang. 1998; 62: 107-26. PMid:9570882 http://dx.doi.org/10.1006/brln.1997.1890

[61] Pasheck GV. Gestural facilitaton of noun and verb retrieval in phasia: A case study. Brain Lang. 1998; 65: 177-80.

[62] Raimer AM, Singletary F, Rodriguez A, Ciampitti M, Heilman KM, Rothi LJ. Effects of gesture + verbal treatment for noun and verb retrieval in aphasia. J In Neurospychol Soc. 2006; 12: 867-82.

[63] Rose M, Douglas J, Matyas T. The comparative effectiveness of gesture and verbal treatmens for specific phonoligc naming impairment. Aphasiol. 2002; 16: 1001-30. http://dx.doi.org/10.1080/02687030143000825

[64] Hyndman D, Pickering RM, Ashburn A. The influence of attention deficits on functional recovery post stroke during the first 12 months after discharge from hospital. J Neurol Neurosurg Psychiatry. 2008; 79: 656-63. PMid:17872979 http://dx.doi.org/10.1136/jnnp.2007.125609

[65] Stapleton T, Ashburn A, Stack E. A pilot study of attention deficits, balance control and falls in the subacute stage following stroke. Clin Rehab. 2001; 15: 437-44. PMid:11518445 http://dx.doi.org/10.1191/026921501678310243

[66] Arvanitakis Z, Leurgans SE, Barnes LL, Bennett DA, Schneider JA. Microinfarct pathology, dementia, and cognitive systems. Stroke. 2011; 42: 722-7. PMid:21212395 http://dx.doi.org/10.1161/STROKEAHA.110.595082

[67] Boysen G, Krarup LH, Zeng X, Oskedra A, Korv J, Andersen G.Gluud C, Pedersen A, Lindahl M, Hansen L, Winkel P, Treulsen T, ExStroke Pilot Trial Group. Exstroke pilot trial of the effect of repeated instructions to improve physical activity after ischaemic stroke: A multinational randomised controlled clinical trial. BMJ. 2009; 339: 1-8. http://dx.doi.org/10.1136/bmj.b2810

[68] Ostwald SK, Hersch G, Keley C, Godwin KM. Evidence-based educational guidelines for stroke survivors after discharge home. J Neurosci Nurs. 2008; 40: 173-91. PMid:18578276 http://dx.doi.org/10.1097/01376517-200806000-00008

[69] vanTil JA, Drossaert CH, Renzenbrink GJ, Snoek GJ, Dijkstra E, Stiggelbout AM, Ijzerman MJ. Feasibility of web-based decision aids in neurological patients. J Telemed Telecare. 2010; 16: 48-52. PMid:20086268 http://dx.doi.org/10.1258/jtt.2009.001012

[70] Podell K, Gifford K, Bougakov D, Goldberg E. Neuropsychological assessment in traumatic brain injury. Psychiatric Clinics of North America. 2010; 33: 855-76. PMid:21093682 http://dx.doi.org/10.1016/j.psc.2010.08.003

[71] Dale E. Audiovisual Methods in Teaching (3rd ed.). New York, NY: Hole, Rinehart, \& Winston, 1969.

[72] National Center for Education Statistics. Key concepts and features of the 2003 national assessment of health literacy [Internet]. 2009. Available from: http://dese.mo.gov/divcareered/AEL/AEL_KeyConcepts.pdf 